\title{
Prevalence, Awareness, Treatment and Control of Hypertension in Tshela Rural Areas. Democratic Republic of The Congo
}

\author{
Blaise Makoso Nimi ${ }^{1,2}$, Gedeon Longo Longo ${ }^{3}$, Benjamin Longo Mbenza ${ }^{1,3}$, Memoria Makoso Nimi ${ }^{2}$, Bienvenu \\ Nkongo Mabiala ${ }^{2,4}$, Elysée Buanga Khuabi ${ }^{2}$ and Jean -Marie Nimi Mbumba ${ }^{5}$ \\ ${ }^{1}$ Department of Internal Medicine, Faculty of Medicine, Kinshasa University, Kinshasa, Democratic Republic of Congo \\ ${ }^{2}$ Kasa Vubu University, Faculty of Medicine, Boma, DRCongo \\ ${ }^{3}$ Lomo-Medical Center, Kinshasa, DRCongo \\ ${ }^{4}$ Higher Institute of Medical Technology (ISTM), Tshela \\ ${ }^{5}$ School of Public Health, University of Kinshasa, DRCongo \\ DOI: 10.29322/IJSRP.10.06.2020.p10294 \\ http://dx.doi.org/10.29322/IJSRP.10.06.2020.p10294
}

\begin{abstract}
BACKGROUND AND AIM: Order to plan by the authorities in our country with limited resources, we have a study to assess the prevalence, awareness, control and factors associated with hypertension in rural Tshela, located in the southern part western DRC

METHODS: we conducted a cross-sectional study using a modified WHO STEP wise questionnaire for data collection during face-to face interviews was conducted from October, 1 to December 15, 2018. A multistage cluster sampling method was used and inclusion criteria were age $\geq 18$ years and informed consent. Information on demographic parameters, behavioral lifestyles, anthropometric and blood pressure (BP) measurements was obtained. Hypertension was defined as an average of two BP $\geq 140 / 90 \mathrm{mmHg}$ or self-reported history of antihypertensive medication use. Independent factors associated with hypertension were identified using logistic regression analysis. $\mathrm{P}<0.05$ defined the level of statistical significance.

RESULTS: The prevalence of hypertension was $34.5 \%$ with $56,1 \%$ of hypertensive participants being unaware of their hypertension status. Of those who were aware and on treatment, only $22,6 \%$ had a controlled BP. Older age $(\mathrm{p}<0.001)$, ATS ( $<<=$ $0.001)$ and $\mathrm{DS}(\mathrm{p}<0.001)$ emerged as main cardiovascular risk factors associated with hypertension.

CONCLUSION we reported high prevalence, low awareness and suboptimal BP control, high cardiovascular risk and associated with smoking and obesity as modifiable risk factors. Therapeutic lifestyle changes and pharmacological treatment are necessary for hypertensive participants.

Hypertension was characterized by a high prevalence, low rate of awareness and suboptimal BP control, high cardiovascular risk and associated with smoking and obesity as modifiable risk factors. Therapeutic lifestyle changes and pharmacological treatment are needed for those hypertensive participants with increased global cardiovascular risk.
\end{abstract}

Index Terms- hypertension, prevalence, awareness, tshela

\section{INTRODUCTION}

$\mathrm{H}$ ypertension is a major risk of disease risk 1. according to the World Health Organization estimates that approximately $40 \%$ of adults suffer from hypertension2. he is responsible Each year, 9.4 million deaths from complications either from heart disease or from stroke (BP) 3, 4 .

The literature reports a gradual increase in the global prevalence of hypertension due to an aging population, the adoption of an unhealthy lifestyle 5. Hypertension being the risk factor contributing the most to the burden of disease, the importance prevention, diagnosis and adequate control of hypertension is more than ever emphasized. Globally, however, less than half of all people are aware of their diagnosis and less than a third of people on treatment have controlled BP6,7.

n sub-Saharan Africa (SSA), its prevalence can reach $38 \%$ in certain communities 8,9. but it is estimated that between 10 and 20 million can suffer from hypertension. These estimates are based on estimates as many sub-Saharan African countries still lack recent and detailed baseline data on the prevalence of HTN 10. In addition, few available studies report low awareness, low rates of patients on treatment and a low rate of hypertensin control in these populations.

In our country the Democratic Republic of Congo (DRC), the nationwide prevalence of hypertension and associated risk factors is not yet available due lack of an effective nationwide surveillance system and financial constraints; however, studies conducted in some urban and rural areas have reported a prevalence of hypertension ranging from $30 \%$ to $40 \%$ and an increased CV mortality due, among others, to low awareness, under-diagnosis and under-treatment as well as poor hypertension control $^{11-14}$. If studies have been conducted in port cities like Kinshasa, Bukavu, Matadi and Boma, there is no data yet available on hypertension and risk factors associated with Tshela, DRC 


\section{METHODS}

- Study design

We conducted a cross-sectional study based on a randomly selected adult population

- Study setting

Tshela is a City located at $250 \mathrm{Km}$ far from Matadi, the Capital City of the south western Province of Kongo Central and $690 \mathrm{Km}$ far Kinshasa, the Capital City of DRC.

Study population

A multistage stratified sampling method was used to allow estimates by sex (male and female) and residence (urban and rural). A total of 1000 eligible individuals were successfully interviewed among the households that gave informed consent.

- Inclusion criteria

Was included in this study any person over the age of 18 , having resided in Tshela over 1 year and having consented verbally or in writing.

- Data collection

The relevant parameters including socio-demographic data, anthropometric and behavioral measures were obtained after the interview by trained personnel..

\section{Measures}

The anthropometric measurements (such as body weight, waist circumference, height) blood pressure, and pulse rate were collected by well-trained Medical students. Blood pressure was measured using digital blood pressure meters (OMRON MIT5 Connect, Kyoto, Japan). The average of the two measures was used in the final analysis.

The size was measured, in a standing position, in a participant without shoes, using a flexible measuring tape (Hemostyl, Sulzbach, Germany).Body weight was also measured with individuals wearing light clothing or standing without shoes using adigital weighing scale (Deluxe GBS-721;Seca Deutschland, Hamburg, Germany). Body mass index (BMI) was computed as weight in kilograms divided by height in meters squared $\left(\mathrm{Kg} / \mathrm{m}^{2}\right)$. A flexible measuring tape was used to measure the size at the level connecting the two iliac crests.

During the survey, questionnaires on eating habits, risky behavior (smoking and smoking, lack of consumption of fruits and vegetables) and physical activities were administered.

\section{- Operational definitions}

The socio-economic level was calculated on the basis of DRC Demographic and Health Survey (DHS) and classified into three degrees : low, middle and high socioeconomic status (SES) $)^{15}$ . The cardiovascular risk factors were defined according to the surveillance manual ${ }^{16}$. Talking alcohol was defined as consumption of more than 1 standard drink (which is the amount of alcohol you find in a small beer, one glass of wine, or one tot of spirits per day for females and more than 2 standard drinks for males $^{16}$. Smoking was defined as the frequent use of tobacco in all forms (smoked, prized) ${ }^{18}$. The BMI was further classified into four categories; underweight (BMI $<18.5 \mathrm{Kg} / \mathrm{m} 2$ ), normal (BMI $18.5-24.99 \mathrm{Kg} / \mathrm{m}^{2}$ ), overweight (BMI $25-29.99 \mathrm{Kg} / \mathrm{m}^{2}$ ) and obese (BMI $\geq 30 \mathrm{Kg} / \mathrm{m}^{2}{ }^{19}$. Diabetes was defined as currently taking antidiabetic drugs or having a fasting capillary whole blood glucose value $\geq 126 \mathrm{mg} / \mathrm{dL}^{20}$. Hypertension was defined as a BP $\geq 140 / 90 \mathrm{~mm} \mathrm{Hg}$, hypertensive subjects was defined by selfreporting ongoing treatment ${ }^{21}$. The hypertension was defined as controlled when SBP $<140 \mathrm{mmHg}$ and DBP $<90 \mathrm{mmHg}$ under pharmacological treatment. Low fruit/vegetable consumption of less than 5 portions of fresh and/or cooked fruits/vegetables a day 22. Insufficient physical activity was defined as self-reported less than $150 \mathrm{~min}$ of moderate intensive activity or less than $75 \mathrm{~min}$ vigorous intensive physical activity per week, including walking and cycling ${ }^{23}$.

\section{Data analyses}

Data were analyzed using Statistical Package for the Social Sciences (SPSS) version 21 for Windows (SPSS Inc., Chicago, IL, United States). Data were expressed as mean values \pm standard deviations (SD) for continuous variables. Frequencies (n) and percentages $(\%)$ were reported for categorical variables. Counts (frequency $=\mathrm{n}$ ) and percentages (\%) were reported for categorical variables. Percentages were compared using the chi-square test. The logistic regression model analysis adjusted for obesity, physical activity, dietary practices, parity, income and alcohol use. A p-value of $<0.05$.

\section{- Data analyses}

Data were analyzed using Statistical Package for the Social Sciences (SPSS) version 21 for Windows (SPSS Inc., Chicago, IL, United States). Data were expressed as mean values \pm standard deviations (SD) for continuous variables. Frequencies (n) and percentages $(\%)$ were reported for categorical variables. Counts (frequency $=\mathrm{n}$ ) and percentages $(\%)$ were reported for categorical variables. Percentages were compared using the chi-square test. The logistic regression model analysis adjusted for obesity, physical activity, dietary practices, parity, income and alcohol use. A p-value of $<0.05$.

\section{Ethical approval}

Obtained from the Ethical Committee of the Ministry of Health ( $\left.\mathrm{N}^{\circ} 150 / \mathrm{CNES} / \mathrm{BN} / \mathrm{PMMF} / 2019\right)$. Consent was taken from the subjects who volunteered to participate in the study. Identified hypertensive subjects were referred to the nearby clinic for treatment

\section{RESULTS}

\section{Table1. General characteristics}

Of the 1000 participants, 372 (37.2\%) were males while 628 $(62.8 \%)$ were females. Their mean age was $47,7 \pm 16,0$ years with $34,9 \%, 21,6 \%, 19,6 \%$ and $23,9 \%$ participants aged participants aged respectively $<40$ years, $40-49$ years, $50-59$ years and $\geq 60$ years . The proportion of unemployed, married, single, secondary education level and low SES participants was 39.7\%, 70.1\%, $8.9 \%, 51.1 \%$ and $61.4 \%$, respectively. Average levels of SBP, DBP, HR, BMI, WC, and capillary blood glucose were $127,2 \pm 22,9 \mathrm{mmHg}, \quad 78,7 \pm 15,7 \mathrm{mmHg}, \quad 80,3 \pm 10,6 \mathrm{bpm}$, $23,5 \pm 4,9 \mathrm{Kg} / \mathrm{m}^{2}, 81.7 \pm 11.9 \mathrm{~cm}$ and $118,1 \pm 31,1 \mathrm{mg} / \mathrm{dl}$, respectively. Table 2 summarizes cardiovascular risk factor profile of the study population as a whole and by BP categories. In the study population as a whole, Smoking $21.5 \%$, alcohol intake (31.3\%), obesity $(11.0 \%)$, central obesity $(38.1 \%)$ and low Fruits and 
vegetables consumate $(71.1 \%)$ were cardiovascular risk factors most frequently reported by the participants.

- Prevalence and Awareness, treatment and control of hypertension (Fig.1),

Hypertension was observed in 345 (34.5\%) participants

Of the 345 hypertensive patients, 144 (41.7\%) knew each other hypertensive and among them heard there were more women. were aware $(45.5 \%$ vs $37.9 \%$; $\mathrm{p}<0.001)$ (Table 3$)$. Current pharmacologic antihypertensive treatment was reported by $62(85.4 \%)$ of 144 participants aware of their hypertension status. The antihypertensive regimen was based on 1 and 2 antihypertensive drugs in $53(72.8 \%)$ and $9(14.6 \%)$ treated hypertensive participants, respectively; no participant was receiving $\geq 3$ antihypertensive drugs.

In those receiving one antihypertensive drug, calcium channel blockers (50.9\%) was the drug class most frequently reported by participants whereas the combination of calcium channel blockers $(\mathrm{CCB})$ and angiotensin converting enzyme inhibitors (ACEIs) (49.1\%). BP control was observed in 14 (22.6 $\%)$ of 144 treated hypertensive participants mainly in men than women (34.8 vs12.1; $\mathrm{p}=0.001)$.

Factors associated with hypertension

In univariate analysis (Table 3), cardiovascular risk factors significantly associated with hypertension were older age $(p=<0.001)$, smoking $(p=<0.001)$, menopause $(p=<0.001)$ ATS $(p<0,001)$,Overweight $(p<0.001)$ obesity $(p=0.001)$, and central obesity $(\mathrm{p}<0.001)$ emerged as the main cardiovascular risk factors significantly associated with hypertension. In multivariate analysis (Table 4), the strength of the associations observed in univariate analysis persisted only for older age [aOR 2,98(2,05$4,35) ; \mathrm{p}=<0.001)$ ], ATS [aOR 8,90(5,65-14,02); $\mathrm{p}=<0.001$ ] and obesity (aOR2,68(1,92-3,17) ; $\mathrm{p}=0.001]$. Thus, the likelihood of having hypertension was nearly three-fold greater in the presence of older age (aOR 2, 8; 95\% CI 2.98(2.05-4.35; $\mathrm{p}=<0.001)$

\section{DISCUSSION}

This study was conducted following the STEPS of the WHO on the assessment of rick for non-communicable diseases and associated factors in rural population.The study on hypertension, like the other studies carried out in the RDC, showed a high prevalence in the general population $(35.5 \%)^{14}$.

The majority of previous studies report a higher prevalence of HNT in urban areas than in rural areas, because rural African populations have a traditional lifestyle associating cultural and dietary habits allowing prevention against of HNT, $(38 \%$ in rural areas vs $41 \%$ in urban zones in 2014) $)^{12}$ but Makoso et al. find a high prevalence in rural areas in in 2020 in Boma $(73.6 \%)^{14}$.

A similar prevalence has been reported from HTN in Nigeria, South Africa, Tanzania, Uganda and Ghana ${ }^{25-29}$.This prevalence will be explained by the progressive aging of the population and the increase in life expectancy in African countries. Age, BMI, sedentary lifestyle, smoking and alcohol consumption are the factors generally associated with hypertension Most of them have already been identified as important risk factors for hypertension in different studies conducted in $\mathrm{SSA}^{30-34}$.
Our results corroborate those of the literature on some of these observed associations such as advancement in age, physical inactivity and BMI. Our study does not establish an association between smoking and hypertension, while tobacco is recognized as a risk factor for CVD

Increased age is one of the strongest risk factors for the development and progression of hypertension. Indeed, the ageing process can increase BP through several mechanisms including insulin resistance/ hyperinsulinemia and subsequent activation of the sympathetic nervous system and renin angiotensin aldosterone system, clustering of multiple risk cardiovascular risk factors, oxidative stress and subsequent inflammation and endothelial dysfunction, increased renal proximal tubular sodium and water reabsorption mediated by the activation of sodium-proton exchanger ${ }^{35,36}$.Like aging, overweight and obesity also can increase BP through insulin resistance/hyperinsulinemia and their subsequent hemodynamic, metabolic and renal consequences ${ }^{37}$. Alcohol consumption, a well-known risk factor for HTN, was not significantly reported in our analyzes 21 , while several studies in sub-Saharan Africa have established a positive association between HTN and moderate to heavy consumption of alcohol ${ }^{38,39}$. In our study, less than $58.2 \%$ of hypertensive participants were aware of their pathology and less than one-half of them took antihypertensive treatments.

The study shows that 1 in 3 patients has controlled hypertension with antihypertensive drugs, this observation is frequent in African studies ${ }^{8,11}$.

The proportion of participants aware, treated and controlled was low in the present study. Our finding is consistent with that of previous studies conducted in the Democratic Republic of the Congo ${ }^{11-14}$. Our finding of low proportion of participants aware of their hypertension is consistent with previous reports from our setting. In this regard, awareness rates of $32,5 \%$, and $42.5 \%$ have been already reported by M'Buyamba-Kabangu et al. in Kinshasa, the capital City ${ }^{40}$ and Katchunga et al. in Bukavu, a City located at the southern East part of DRC, respectively ${ }^{12}$. Low awareness remains still a big challenge for the control of hypertension in other sub-Saharan African countries and requires effective behavioral change communication and screening strategies to reduce the prevalence of undiagnosed hypertension and related life-threatening complications $\mathrm{s}^{41,42}$.

The low proportion of participants on antihypertensive therapy in the present study is consistent with previous studies from DRC and other sub-Saharan African countries ${ }^{11-13}$ that reported values less than $50 \%$ among treated patients. Similar picture has been found for patients who achieved recommended BP goals.

The majority of treated participants were receiving monotherapy with mainly calcium channel blockers. If the use a calcium channel blocker or a thiazide diuretic as first-line drug in the treatment of hypertension of blacks, known to have a low plasma renin activity and a subsequent volume-dependent hypertension ${ }^{43}$.

Older age and FH-HT as non-modifiable and smoking, overweight and obesity as modifiable risk factors were independent factors associated with hypertension. Older age has been reported to be one of the most powerful cardiovascular risk factors through oxidative stress-induced endothelial dysfunction ${ }^{36}$ 
and subsequent vascular remodeling as well as the coexistence of multiple cardiovascular risk factors via insulin resistance ${ }^{35}$.

The association of FH-HT and hypertension does translate the existence of a potential genetic susceptibility that does interact with environmental factors for the development and progression of hypertension and related end-organ damage ${ }^{44}$. Smoking ${ }^{45}$ and overweight/obesity are well-known traditional risk factors sharing insulin resistance, sympathetic nervous (SNS) and renin angiotensin aldosterone (RAAS) systems, oxidative stress and subsequent inflammation and endothelial dysfunction as a common pathogenic pathway for cardiac and vascular damage ${ }^{46}$. The interpretation of the results of the present survey should take into account of some limitations. First, the cross-sectional design of the survey precludes the establishment of any temporal relationship between the outcome and the variables of interest. Second, the unique measurement of the variables of interest could have under- or overestimated their true values and the prevalence of hypertension. Third, other factors usually associated with hypertension such as blood lipids were not measured.

\section{CONCLUSION}

The present survey showed that nearly four participants out of ten had hypertension that was associated with older age, family history of hypertension, overweight and obesity as main cardiovascular risk factors. A management strategy based on both therapeutic lifestyle changes (TLC) and pharmacological treatment is needed for those hypertensive participants with increased global cardiovascular risk.

\section{ACKNOWLEDGMENT}

The authors would like to express their deepest gratitude to the Administrative Authorities of Tshela City and to all the students who took part in the survey

\section{CONFLICT OF INTEREST}

No

\section{AUTHOR'S CONTRIBUTION}

BMN participated in survey conception and data collection and management; drafted the manuscript.

GLL, BLB, MMN participated in survey conception and data analysis; revised the manuscript.

GLL conducted data analysis and revised the manuscript.

$\mathrm{RV}$ revised the manuscript.

JMN revised the manuscript.

EBK participated in survey conception and revised the manuscript

\section{REFERENCES}

[1] 1. GBD 2016 Risk Factors Collaborators. Global, regional, and national comparative risk assessment of 84 behavioural, environmental and occupational, and metabolic risks or clusters of risks, 1990-2016: a systematic analysis for the Global Burden of Disease Study 2016. Lancet 390, $1345-1422$.

[2] 2. World Health Organization. A global brief on Hypertension 2013.

[3] 3. World Health Organization. Global status report on non communicable diseases 2011.

[4] 4. Ivers, N. et al. Audit and feedback: effects on professional practice and healthcare outcomes. Cochrane Database Syst Rev, CD000259, 10.1002/14651858.CD000259.pub3 (2012).

[5] 5. Forouzanfar MH, et al. Global Burden of Hypertension and Systolic Blood Pressure of at Least 110 to $115 \mathrm{~mm} \mathrm{Hg}, 1990-2015$. JAMA. 2017;317:165182.

[6] 6. Chow CK, et al. Prevalence, awareness, treatment, and control of hypertension in rural and urban communities in high-, middle-, and lowincome countries. JAMA. 2013;310:959-968

[7] 7. Olsen $\mathrm{MH}$, et al. A call to action and a lifecourse strategy to address the global burden of raised blood pressure on current and future generations: the Lancet Commission on hypertension. Lancet. 2016;388:2665-2712.

[8] 8. Opie LH, Seedat YK. Hypertension in sub-Saharan African populations. Circulation. 2005;112(23):3562-8.

[9] 9. Steyn K, Bradshaw D, Norman R, Laubscher R. Determinants and treatment of hypertension in south Africans: the first demographic and health survey. S Afr Med J. 2008;98(5):376-80.

[10] 10. Hendriks ME, Wit FW, Roos MT, Brewster LM, Akande TM, de Beer $\mathrm{IH}$, et al. Hypertension in sub-Saharan Africa: cross-sectional surveys in four rural and urban communities. PLoS One. 2012;7(3):e32638.

[11] 11. Bayauli MP, M'Buyamba-Kayama JR, Ngoyi NG, Lepira FB, Kayembe $\mathrm{KP}$, Lemogoum D, et al. Trends in prevalence of obesity and hypertension in an urban Congolese community. Journal Epidemiological Research 2018; 4(1): $33-40$

[12] 12Katchunga PB, Mirindi P, Baleke P, Ntaburhe T, Twagirumukiza M, M'Buyamba-Kabangu JR. The trend in blood pressure and hypertension prevalence in the general population of South Kivu between 2012 and 2016: Results from two representative cross-sectional surveys - The Bukavu observational study. PLoS ONE 14(8):e0219377.

[13] 13.Kianu B, Mpembele E, Kintoki EV, Makulo JR, Kiazayawoko FZ, Manyebwa KJDD, et al. Rates of hypertension prevalence, awareness, treatment, and control in Congolese South West Port City.The influence of gender according to groups. Global Journal of Medical Research 2015; 15 (1):1-8

[14] 14 Blaise Makoso Nimi, François Lepira Bompeka, Aliocha Nkodila, Williams Ilenga,Gédeon Long-Longo, Dieudonné Vangu Ngoma,et al . Prehypertension, Hypertension and Associated Risk Factors among Adults Living in the Port City of Boma in the Democratic Republic of the Congo. A Population-Based Cross-Sectional Survey". Acta Scientific Cancer Biology 4.5 (2020): $24-32$

[15] 15. "2013-2014 Democratic Republic of the Congo Demographic and Health Survey (DHS)". Ministry of Heath and Ministry of Planification, preliminary May (2014).

[16] 16. Word Health Organisation TWSatndrfsIW, Available at: http://www.who.int/ncds/surveillance/steps/STEPS_Manual.pdf?ua=1 2017.

[17] 17. Takeshi K, laria P, Maufroy N, Jean philippe D, Isabelle M Fakher N, et al. arterial hypertension and arterial pulse. Mt cardio. 2006 ; 2 (5): 493-501.

[18] 18. Orth SR, Stockmann A, Conradt C, Ritz E, Ferro M, Kreusser W and al. Smoking as a risk factor for end-stage renal failure in men with primary renal disease. Kidney Int. 2008; 54: 926-31.

[19] 19. World Health Organization (WHO). The problem of overweight and obesity: preventing and managing the global epidemic. Report Series 894; Geneva, WHO, 2000: 537

[20] 20. Definition and diagnosis of diabetes mellitus and intermediate hyperglycaemia Report of a WHO/IDF January 2006.

[21] 21Williams B, Mancia G, Spiering W, Agabiti Rosei E, Azizi M, Burnier M, et al. $2018 \mathrm{ESC} / \mathrm{ESH}$ guidelines for the management of arterial hypertension. Eur Heart J. 2018;39(33):3021-104.

[22] 22. Mohsen Gadallah , Soad Abdel , Amira Mohsen and Sahar Kandil. Hypertension and associated cardiovascular risk factors among urban slum dwellers in Egypt: a population-based survey.East Mediterr Health J. 2018;24(5):435-442.

[23] 23. World Health Organization. "Global Physical Activity Questionnaire (GPAQ)". Geneva, Switzerland. 
[24] 24. Guwatudde D, Nankya-Mutyoba J, Kalyesubula R, Laurence C, Adebamowo C, Ajayi IO. The burden of hypertension in sub-Saharan Africa: a four-country cross sectional study. BMC Public Health (2015) 15:1211 DOI 10.1186/s12889-015-2546-z

[25] 25. Nansseu JR, Kameni BS, Assah FK, Bigna JJ, Petnga SJ, et al. Prevalence of major cardiovascular disease risk factors among a group of sub-Saharan African young adults: a population-based cross-sectional study in Yaoundé, Cameroon. BMJ Open. 2019 Oct 7;9(10):e029858. doi: 10.1136/bmjopen2019-029858.

[26] 26. Nuwaha F, Musinguzi G. Pre-hypertension in Uganda: a cross-sectional study. BMC Cardiovasc Disord. 2013 Nov 14; 13:101. doi: 10.1186/14712261-13-101.

[27] 27. Irazola EZ. Hypertension Prevalence, Awareness, Treatment, and Control in Selected Communities of Nine Low- and Middle Income Countries: Results From the NHLBI/UHG Network of Centers of Excellence for Chronic Diseases. Glob Heart. 2016 March; 11(1): 47-59.

[28] 28. Owiredu EW, Dontoh E, Essuman, Bazanfara BB. Demographic and Lifestyle Predictors of Prehypertension: A Cross-Sectional Study among Apparently Healthy Adults in Kumasi, Ghana. Biomed Res Int. 2019 Apr 23; 2019:1764079. doi: 10.1155/2019/1764079. eCollection 2019.

[29] 29. Isezuo SA, Sabir AA, Ohworvorilole AE, Fasanmade OA. Prevalence, associated factors and relationship between prehypertension and hypertension: a study of two ethnic African populations in Northern Nigeria. J Hum Hypertens 2011; 25(4): 224-30.

[30] 30. Pires JE, Sebastiao YV, Langa AJ, Nery SV. Hypertension in northern Angola: prevalence, associated factors, awareness, treatment and control. BMC Public Health. 2013;13:90.

[31] 31.Wamala JF, Karyabakabo Z, Ndungutse D, Guwatudde D. Prevalence factors associated with hypertension in Rukungiri district, Uganda--a communitybased study. Afr Health Sci. 2009;9(3):153-60.

[32] 32 Helelo TP, Gelaw YA, Adane AA. Prevalence and associated factors of hypertension among adults in Durame town, Southern Ethiopia. PLoS One. 2014;9(11):e112790.

[33] 33.Adeloye D, Basquill C. Estimating the prevalence and awareness rates of hypertension in Africa: a systematic analysis. PLoS One. 2014;9(8):e104300.

[34] 34. Hamid S, Groot W, Pavlova M. Trends in cardiovascular diseases and associated risks in sub-Saharan Africa: a review of the evidence for Ghana, Nigeria, South Africa, Sudan and Tanzania. Aging Male. 2019;1:1-8.

[35] 35. Ramos R, Marrugat $J$, Basagana $X$, et al. The role of aging in cardiovascular risk factor clustering in non-diabetic population free of coronary heart disease. Eur J Clin Epidemiol 2004; 109(23 Suppl): III-15-19.

[36] 36.Plante GE. Impact of aging on the body's vascular system. Metabolism 2003; 52(10 Suppl): 31-5.

[37] 37.Reaven GM, Lithell H, Landsberg L. Hypertension and associated metabolic abnormalities. The role of insulin resistance and the sympathoadrenal system. N Engl J Med 1996; 334(2): 374-381.

[38] 38.Zatu MC, Van Rooyen JM, Kruger A, Schutte AE. Alcohol intake, hypertension development and mortality in black south Africans. Eur J Prev Cardiol. 2016;23(3):308-15.

[39] 39.Chin JH, Twinobuhungiro A, Sandhu A, Hootsmans N, Kayima J, Kalyesubula R. Determinants of raised blood pressure in urban Uganda: a community based case-control study. Ethn Dis. 2017;27(1):15-20.
[40] 40.M'Buyamba-Kabangu JR,Fagard R, Staessen J. Blood pressure in Bantu of zaire: Epidemiological aspects. Tropical Cardiology $1987 ; 13: 113-120$.

[41] 41.Prashant K, Dalsone K, Tamara DC, Jane K, Elvin HG, Vivek J, et al. Epidemiology and awareness of hypertension in a rural Uganda community: a cross-sectional study. BMC Public Health 2013; 13: 1151-61.

[42] 42.James K, Rhoda KW, Achilles K, Eli L, Fred N. Hypertension awareness, treatment and control in Africa: a systematic review. BMC Cardiovascular Disorders 2013; 13: 54-65.

[43] 43. M'Buyamba-Kabangu JR, Anisiuba BC, Ndiaye MB, Lemogoum D, Jacobs L, Ijoma CK, et al. Efficacy of newer versus older antihypertensive drugs in black patients living in sub-Saharan Africa. J Hypertens $2013 ; 27$, 729-735.

[44] 44.Nadkarni GN, Galarneau G, Ellis SB, Nadukuru R, Zhang J, Scott SA, et al. Apolipoprotein L1 Variants and Blood Pressure Traits in African Americans. J Am Coll Cardiol. 2017 Mar 28; 69(12): 1564-1574.

[45] 45.Virdis A, Giannarelli C, Neves MF, Taddei S, Ghiadoni L. Cigarette smoking and hypertension. Curr Pharm Des. 2010; 16(23):2518-25.

[46] 46.Reaven GM, Lithell H, Landsberg L. Hypertension and associated metabolic abnormalities--the role of insulin resistance and the sympathoadrenal system. N Engl J Med. 1996 Feb 8; 334(6):374-81.

\section{AUTHORS}

First Author - Blaise Makoso Nimi, Department of Internal Medicine, Faculty of Medicine, Kinshasa University, Kinshasa, Democratic Republic of Congo

Second Author - Gedeon Longo Longo, Lomo-Medical Center, Kinshasa, DRCongo

Third Author - Benjamin Longo Mbenza, Lomo-Medical

Center, Kinshasa, DRCongo

Fourth Author - Memoria Makoso Nimi, Kasa Vubu

University, Faculty of Medicine, Boma, DRCongo

Fifth Author - Bienvenu Nkongo Mabiala, Higher Institute of Medical Technology (ISTM), Tshela

Sixth Author - Elysée Buanga Khuabi, Kasa Vubu University, Faculty of Medicine, Boma, DRCongo

Seventh Author - Jean -Marie Nimi Mbumba, School of Public Health, University of Kinshasa, DRCongo

Corresponding Author:

Blaise Makoso, MD

University of Kinshasa Hospital

University of Kinshasa

PO Box 123 Kin XI

E-mail: docteurmakoso@gmail.com

\section{ANNEXES}

Table 1. General characteristics of the study population as a whole and by hypertension status.

Table 2. Cardiovascular risk profile of the study population as a whole and by hypertension status.

Table 3. Awareness, treatment and control of hypertension of the study population as a whole and by hypertension status.

Table 4. Cardiovascular risk factors associated with hypertension in univariate and multivariate analysis.

Figure 1. Distribution of study population according to blood pressure status.

This publication is licensed under Creative Commons Attribution CC BY. 
Table 1. General characteristics of the study population as a whole and by hypertension status.

\begin{tabular}{|c|c|c|c|c|}
\hline Variables & $\begin{array}{l}\text { Over All } \\
\mathbf{n}=1000\end{array}$ & $\begin{array}{l}\text { Male } \\
n=372\end{array}$ & $\begin{array}{l}\text { Female } \\
n=628\end{array}$ & $\bar{P}$ \\
\hline Age, years & $47,7 \pm 16,0$ & $49,4 \pm 15,4$ & $46,7 \pm 16,3$ & $<0.007$ \\
\hline Age categories, n(\%) & & & & $<0.001$ \\
\hline$<40$ years & $349(34,9)$ & $114(30,6)$ & $235(37,4)$ & \\
\hline $40-49$ years & $216(21,6)$ & $73(19,6)$ & $143(22,8)$ & \\
\hline $50-59$ years & $196(19,6)$ & $75(20,2)$ & $121(19,3)$ & \\
\hline$\geq 60$ years & $239(23,9)$ & $110(29,6)$ & $129(20,5)$ & \\
\hline Occupation, $\mathrm{n}(\%)$ & & & & $<0.001$ \\
\hline Senior Staff & $30(3,0)$ & $23(6,2)$ & $7(1,1)$ & \\
\hline Businessmen & $351(35,1)$ & $131(35,2)$ & $220(35,0)$ & \\
\hline Students & $24(2,4)$ & $15(4,0)$ & $9(1,4)$ & \\
\hline Public Servants & $198(19,8)$ & $124(33,3)$ & $74(11,8)$ & \\
\hline Unemployed & $397(39,7)$ & $79(21,2)$ & $318(50,6)$ & \\
\hline Marital status, $\mathrm{n}(\%)$ & & & & $<0.001$ \\
\hline Married & $700(70,1)$ & $295(79,3)$ & $405(64,7)$ & \\
\hline Divorced & $70(7,0)$ & $17(4,6)$ & $53(8,5)$ & \\
\hline Widow & $139(13,9)$ & $11(3,0)$ & $128(20,4)$ & \\
\hline Single & $89(8,9)$ & $49(13,2)$ & $40(6,4)$ & \\
\hline Education level, $\mathrm{n}(\%)$ & & & & $<0.001$ \\
\hline Primary/no & $298(29.8)$ & $56(15.1)$ & $242(38.5)$ & \\
\hline Secondary & $510(51,1)$ & $202(54,4)$ & $308(49,0)$ & \\
\hline University/Superior & $191(19,1)$ & $113(30,5)$ & $78(12,4)$ & \\
\hline SES, $n(\%)$ & & & & 0.113 \\
\hline Low & $614(61,4)$ & $220(59,1)$ & $394(62,7)$ & \\
\hline Middle & $341(34,1)$ & $126(33,9)$ & $215(34,2)$ & \\
\hline High & $45(4,5)$ & $26(7,0)$ & $19(3,0)$ & \\
\hline BMI, $\mathrm{Kg} / \mathrm{m}^{2}$ & $23,5 \pm 4,9$ & $22,2 \pm 3,6$ & $24,2 \pm 5,5$ & $<0.001$ \\
\hline
\end{tabular}




\begin{tabular}{|c|c|c|c|c|}
\hline $\mathrm{WC}, \mathrm{cm}$ & $81.7 \pm 11.9$ & $79.7 \pm 10.7$ & $85.4 \pm 13.2$ & $<0.001$ \\
\hline $\mathrm{SBP}, \mathrm{mmHg}$ & $127,2 \pm 22,9$ & $129,8 \pm 21,7$ & $125,7 \pm 23,4$ & $<0.006$ \\
\hline DBP, mmHg & $78,7 \pm 15,7$ & $80,3 \pm 13,2$ & $77,8 \pm 16,9$ & $<0.012$ \\
\hline MAP, $\mathrm{mmHg}$ & $94,9 \pm 16,6$ & $96,8 \pm 15,2$ & $93,8 \pm 17,3$ & $<0.005$ \\
\hline $\mathrm{PP}, \mathrm{mmHg}$ & $48,5 \pm 16,6$ & $49,4 \pm 13,5$ & $47,9 \pm 18,1$ & $<0.163$ \\
\hline $\mathrm{HR}, \mathrm{bpm}$ & $80,3 \pm 10,6$ & $78,4 \pm 12,4$ & $81,4 \pm 9,2$ & $<0.001$ \\
\hline Blood glucose, $\mathrm{mg} / \mathrm{dl}$ & $118.1 \pm 31.1$ & $118.2 \pm 31.9$ & $117.9 \pm 29.7$ & 0.929 \\
\hline
\end{tabular}

Data are expressed as mean \pm standard deviation, median (interquartile range) absolute (n) and relative (in percent) frequency. Abbreviations: M, male F, female SES, socioeconomic status BMI, body mass index WC, waist circumference SBP, systolic blood pressure DBP, diastolic blood pressure MAP, mean arterial blood pressure PP, pulse pressure HR, heart rate bpm, beat per minute

Table 2. Cardiovascular risk factor profile of the study population as a whole and by hypertension

\begin{tabular}{|c|c|c|c|}
\hline FRCV & HTA+ & HTA- & $\mathbf{p}$ \\
\hline & $n=345$ & $n=655$ & \\
\hline Age $>55 \mathrm{H} / 45 \mathrm{~F}, \mathrm{n}(\%)$ & $237(68,7)$ & $208(31,8)$ & $<0,001$ \\
\hline HF-HTA, n(\%) & $88(25,5)$ & $167(25,5)$ & 0,527 \\
\hline HF-DM, n(\%) & $51(14,8)$ & $52(7,9)$ & $\mathbf{0 , 0 0 1}$ \\
\hline HF-Obesite, $\mathrm{n}(\%)$ & $9(2,6)$ & $20(3,1)$ & 0,428 \\
\hline HF- MCV, n(\%) & $16(4,6)$ & $11(1,7)$ & $\mathbf{0 , 0 0 7}$ \\
\hline HF-MRC, n(\%) & $4(1,2)$ & $5(0,8)$ & 0,378 \\
\hline Smoking,, $\mathrm{n}(\%)$ & $93(27,0)$ & $122(18,6)$ & $\mathbf{0 , 0 0 2}$ \\
\hline Alcohol intake, $\mathrm{n}(\%)$ & $113(32,8)$ & $200(30,5)$ & 0,258 \\
\hline Physical inactivity, n(\%) & $114(33,0)$ & $137(20,9)$ & $<0,001$ \\
\hline Goutte, $\mathrm{n}(\%)$ & $12(3,5)$ & $7(1,1)$ & 0,009 \\
\hline Menopause, $\mathrm{n}(\%)$ & $142(41,2)$ & $108(16,5)$ & $<0,001$ \\
\hline ATS, n(\%) & $140(40,6)$ & $32(4,9)$ & $<0,001$ \\
\hline Overweight, n(\%) & $85(24,6)$ & $106(16,2)$ & 0,001 \\
\hline Obesity, n(\%) & $54(15,7)$ & $56(8,5)$ & $\mathbf{0 , 0 0 1}$ \\
\hline Central obesity, n(\%) & $175(50,7)$ & $205(31,3)$ & $<0,001$ \\
\hline $\mathrm{RCM}, \mathrm{n}(\%)$ & $89(25,8)$ & $94(14,4)$ & $<0,001$ \\
\hline
\end{tabular}




$$
\mathrm{DM}, \mathrm{n}(\%) \quad 68(23,1) \quad 58(11,5) \quad<0,001
$$

Data are expressed as absolute (n) and relative (in percent) frequency. Abbreviations: M, male F, female FH, family history HT, hypertension DM, diabetes mellitus CVD, cardiovascular disease PH, personal history CMR, cardiometabolic risk

Table 2. Cardiovascular risk factor profile of the study population as a whole and by hypertension

\begin{tabular}{|c|c|c|c|}
\hline FRCV & HTA+ & HTA- & $\mathbf{p}$ \\
\hline & $n=345$ & $n=655$ & \\
\hline Age $>55 \mathrm{H} / 45 \mathrm{~F}, \mathrm{n}(\%)$ & $237(68,7)$ & $208(31,8)$ & $<0,001$ \\
\hline HF-HTA, n(\%) & $88(25,5)$ & $167(25,5)$ & 0,527 \\
\hline HF-DS, n(\%) & $51(14,8)$ & $52(7,9)$ & $\mathbf{0 , 0 0 1}$ \\
\hline HF-Obésité, n(\%) & $9(2,6)$ & $20(3,1)$ & 0,428 \\
\hline $\mathrm{HF}-\mathrm{MCV}, \mathrm{n}(\%)$ & $16(4,6)$ & $11(1,7)$ & $\mathbf{0 , 0 0 7}$ \\
\hline HF-MRC, n(\%) & $4(1,2)$ & $5(0,8)$ & 0,378 \\
\hline HF-Dyslipidémie, n(\%) & $4(1,2)$ & $11(1,7)$ & 0,712 \\
\hline Tabac, n(\%) & $93(27,0)$ & $122(18,6)$ & 0,002 \\
\hline Alcool, $\mathrm{n}(\%)$ & $113(32,8)$ & $200(30,5)$ & 0,258 \\
\hline Sédentarité, n(\%) & $114(33,0)$ & $137(20,9)$ & $<0,001$ \\
\hline Goutte, $\mathrm{n}(\%)$ & $12(3,5)$ & $7(1,1)$ & 0,009 \\
\hline Ménopause, n(\%) & $142(41,2)$ & $108(16,5)$ & $<0,001$ \\
\hline Athérosclérose subclinique, n(\%) & $140(40,6)$ & $32(4,9)$ & $<0,001$ \\
\hline Tachycardie, $\mathrm{n}(\%)$ & $34(9,9)$ & $81(12,4)$ & 0,140 \\
\hline Surpoids, n(\%) & $85(24,6)$ & $106(16,2)$ & 0,001 \\
\hline Obésité, n(\%) & $54(15,7)$ & $56(8,5)$ & $\mathbf{0 , 0 0 1}$ \\
\hline Obésité abdominale, n(\%) & $175(50,7)$ & $205(31,3)$ & $<0,001$ \\
\hline $\mathrm{RCM}, \mathrm{n}(\%)$ & $89(25,8)$ & $94(14,4)$ & $<0,001$ \\
\hline $\mathrm{DS}, \mathrm{n}(\%)$ & $68(23,1)$ & $58(11,5)$ & $<0,001$ \\
\hline Durée de sommeil, n(\%) & & & 0,005 \\
\hline$<8$ heures & $148(44,0)$ & $215(33,8)$ & \\
\hline 8 heures & $118(35,1)$ & $250(39,3)$ & \\
\hline$>8$ heures & $70(20,8)$ & $171(26,9)$ & \\
\hline
\end{tabular}




$\begin{array}{lrr}\text { Inactif } & 196(56,8) & 354(54,0) \\ \text { Actif } & 194(43,2) & 301(46,0)\end{array}$

Table 3. Awareness, treatment and control of hypertension among hypertensive participants

\begin{tabular}{|c|c|c|c|c|c|}
\hline Variable & $\mathbf{N}$ & All & Male & Female & $\mathbf{P}$ \\
\hline Awareness, n(\%) & 345 & & 145 & 200 & $<0.001$ \\
\hline No & & $201(58.2)$ & $90(62.1)$. & $111(55.5)$ & \\
\hline Yes & & $144(41.7)$ & $55(37.9)$ & $89(45.5)$ & \\
\hline Treatment, $\mathrm{n}(\%)$ & 144 & & 58 & 86 & 0.476 \\
\hline No & & $82(56.9)$ & $32(55.2)$ & $50(58.1)$ & \\
\hline Yes & & $62(43.1)$ & $26(44.8)$ & $36(41.9)$ & \\
\hline Drug regimen/class & 62 & & 29 & 33 & 0.119 \\
\hline 1 drug, $\mathrm{n}(\%)$ & & $53(85.4)$ & $23(79.3)$ & $30(90.9)$ & \\
\hline $\mathrm{CCB}$ & & $27(50.9)$ & $17(73.9)$ & $10(33.3)$ & \\
\hline ACEI & & $26(49.1)$ & $6(26.1)$ & $20(66.7)$ & \\
\hline 2 drugs, $\mathrm{n}(\%)$ & & $9(14.6)$ & $6(20.7)$ & $3(9.1)$ & \\
\hline $\mathrm{CCB}+\mathrm{ACEI}$ & & $8(88.9)$ & $6(100.0)$ & $2(66.7)$ & \\
\hline CCB + Thiazide like & & $1(11.1)$ & $0(0.0)$ & $1(33.3)$ & \\
\hline BP control, n(\%) & 62 & & 29 & 33 & 0,001 \\
\hline No & & $48(77.4)$ & $19(65.5)$ & $29(87.9)$ & \\
\hline Yes & & $14(22.6)$ & $10(34.8)$ & $4(12.1)$ & \\
\hline
\end{tabular}

Data are expressed as absolute (n) and relative (in percent) frequencies. Abbreviations: CCB, calcium channel blocker ACEI, angiotensin converting enzyme inhibitor ARA, angiotensin type 1 receptor antagonist $\mathrm{BP}$, blood pressure 
Tableau 4 Cardiovascular risk factors associated with hypertension in multivariate analysis.

\begin{tabular}{|c|c|c|c|c|}
\hline \multirow[t]{2}{*}{ Variables } & \multicolumn{2}{|c|}{ Univariate } & \multicolumn{2}{|c|}{ Multivariate } \\
\hline & $\mathrm{p}$ & OR (IC95\%) & $\mathrm{p}$ & OR (IC95\%) \\
\hline \multicolumn{5}{|c|}{ Older age, yrs } \\
\hline No & & 1 & & 1 \\
\hline Yes & $<0,001$ & $4,72(3,56-6,25)$ & $<0,001$ & $2,98(2,05-4,35)$ \\
\hline \multicolumn{5}{|l|}{ Smoking } \\
\hline No & & 1 & & 1 \\
\hline Oui & 0,002 & $1,61(1,18-2,20)$ & 0,153 & $1,34(0,90-1,99)$ \\
\hline \multicolumn{5}{|c|}{ Physical inactivity } \\
\hline No & & 1 & & 1 \\
\hline Yes & $<0,001$ & $1,87(1,39-2,50)$ & 0,121 & $1,36(0,92-1,99)$ \\
\hline \multicolumn{5}{|l|}{ Goutte } \\
\hline No & & 1 & & 1 \\
\hline Yes & 0,012 & $3,34(1,30-8,55)$ & 0,604 & $1,35(0,44-4,15)$ \\
\hline \multicolumn{5}{|l|}{ Menopause } \\
\hline No & & 1 & & 1 \\
\hline Yes & $<0,001$ & $3,54(2,64-4,77)$ & 0,145 & $1,36(0,90-2,05)$ \\
\hline \multicolumn{5}{|l|}{ ATS } \\
\hline No & & 1 & & 1 \\
\hline Yes & $<0,001$ & $13,30(8,77-20,14)$ & $<0,001$ & $8,90(5,65-14,02)$ \\
\hline \multicolumn{5}{|l|}{ Overweight } \\
\hline No & & 1 & & 1 \\
\hline Yes & 0,001 & $1,69(1,23-2,34)$ & 0,096 & $1,90(0,17-3,06)$ \\
\hline \multicolumn{5}{|l|}{ Obesity } \\
\hline No & & 1 & & 1 \\
\hline Yes & 0,001 & $1,99(1,33-2,96)$ & 0,009 & $2,68(1,92-3,17)$ \\
\hline
\end{tabular}



No
1
1
Yes
$<0,001$
$2,26(1,73-2,95)$
0,203
$1,33(0,86-2,07)$
DS
No 1
1
Yes $<0,001$
2,53(1,73-3,69)
$<0,001$
$2,34(1,47-3,71)$

Abbreviations : hypertension aOR, adjusted odds ratio CI,

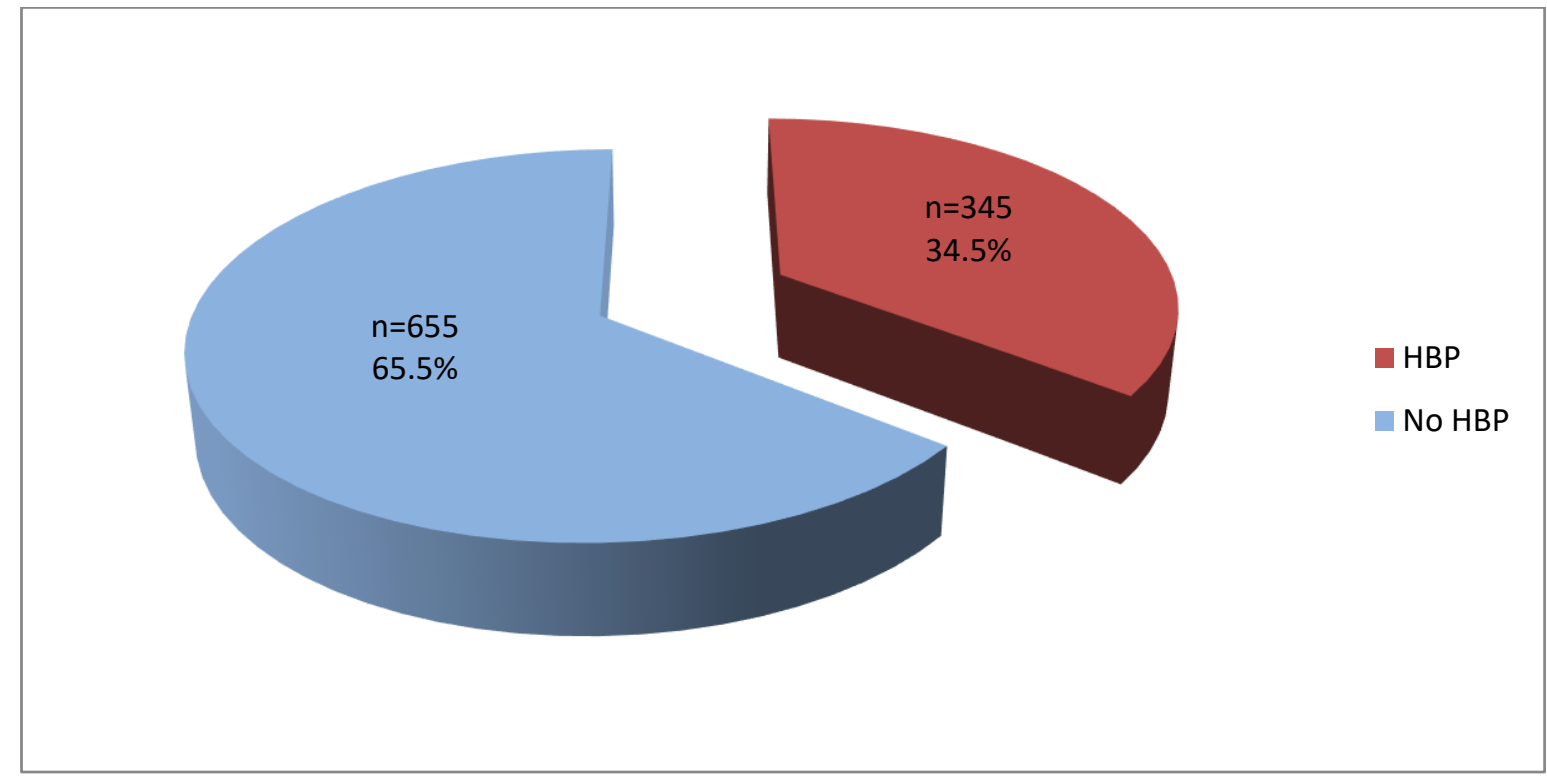

Fig.1. Distribution of the study participants according to hypertension status. Abbreviations: HBP, high blood pressure 